\title{
Forum
}

doi:10.1017/S0373463312000197

\section{The Seabots are Coming Here: Should they be Treated as 'Vessels'?}

\author{
Craig H. Allen \\ (University of Washington, USA) \\ (Email: challen@uw.edu)
}

\begin{abstract}
Unmanned Marine Vehicles (UMVs), like their aerial cousins Unmanned Aerial Vehicles (UAVs), are not easily classified under existing legal regimes. Even though unmanned, should these seagoing drones be treated as 'vessels' under the Law of the Sea Convention articles on navigation rights and duties? Are they 'vessels' under the International Regulations for Preventing Collisions at Sea (COLREGs, 1972)? If so, should they be accorded a manoeuvring priority vis-à-vis other vessels? Are the differences between autonomous UMVs and the increasingly automated manned vessels all that great, such that classification should turn on whether the vessel is manned rather than on how navigation and collision avoidance decisions are made and executed?
\end{abstract}

\author{
KEY WORDS \\ 1. International Regulations for Preventing Collisions at Sea (COLREGs). \\ 2. Unmanned Marine Vehicles (UMVs). 3. Unmanned Surface Vehicles (USVs).
}

4. Unmanned Undersea Vehicles (UUVs).

Submitted: 22 April 2012. Accepted: 24 April 2012. First published online: 30 May 2012.

1. INTRODUCTION. A two-day workshop convened by the US Naval War College in Newport, RI from 20-21 March 2012, focused on the legal issues raised by the advent of Unmanned Marine Vehicles (UMVs) - what some are calling seagoing drones or robots; the acronym UMV includes both Unmanned Surface Vehicles (USVs) and Unmanned Undersea Vehicles (UUVs). A central question posed by the conference was whether USVs and UUVs qualify as 'vessels' under the various legal regimes. To address the issue, the workshop brought together a mix of 25 technical experts and legal scholars and practitioners from Canada, Germany and the UK and USA.

The workshop opened with expert presentations providing an overview of UMVs and the capabilities and employment of those vehicles. Those were followed by presentations and discussions on the legal status of UMVs, COLREG issues raised by 
the operation of UMVs, the navigation rights and responsibilities applicable to those vehicles, and the application of the law of armed conflict to UMVs. The experts then examined two progressively complex scenarios involving the use of UMVs in maritime security applications.

2. UNMANNED MARINE VEHICLES AS 'VESSELS'. The presentations made it clear that UMVs are not a remote future possibility; they have already arrived. Moreover, their actual and planned employment extends well beyond national security applications. It includes, for example, commercial, hydrographic, oceanographic and, perhaps, even illicit smuggling applications. Some UMVs are designed to operate solely on the surface, while others operate fully or partly submerged. The US Navy's master plan for UUVs organizes them into four classes, the largest of which includes vehicles displacing 10 tons (UUV, 2004).

The US Navy master plan for USVs (USV, 2007) presently includes 7 and 11 metre vehicles. Far larger USVs were discussed at the workshop, as was the possibility that some UMVs might one day be weaponized. The level of UMV autonomy ranges from Remotely Operated Vehicles (ROVs) with a human in the loop, to semi-autonomous and fully autonomous versions. Full autonomy is more common in UUVs, where communication with the submerged vehicle is severely restricted. As technologies develop, the complex mix of vessel types, applications and their degree of sophistication and autonomy will almost certainly increase.

As with their better known unmanned aerial cousins - the UAVs - it is not entirely clear how UMVs will be classified under the relevant legal regimes and the following questions arise.

- Do they enjoy the navigation rights of 'vessels' and 'ships' under the UN Convention on the Law of the Sea?

- Must they be registered by a Flag State? Are they entitled to exercise the rights of innocent and transit passage?

- Do naval UMVs enjoy sovereign immunity?

- How should UMVs be treated under the COLREGs?

- Are they 'vessels' within the definition in COLREGs Rule 3(a) [General Definitions]?

- If so, are they entitled to a preferred status under Rule 18 (Responsibilities Between Vessels)?

- If they are not vessels under the present rule (perhaps because some are not intended to serve a "transportation" function), should the Rule 3(a) definition be amended to include them, and thereby unequivocally bring them within the COLREGs regime (as was done with Wing-in-Ground craft in 2003)?

- How will the look-out requirement in Rule 5 (Look-out) be applied to UMVs? What lighting and sound signal requirements will apply to them?

- What are their obligations in restricted visibility?

3. RECOMMENDATIONS OF THE US NAVIGATION SAFETY ADVISORY COUNCIL. The US Navigation Safety Advisory Council (NAVSAC), a group of experts selected and appointed to advise and make 
recommendations to the US Coast Guard on the COLREGs, attempted to address some of these questions in a recent resolution (NAVSAC, 2011). Although the NAVSAC reportedly expressed some doubt as to the classification of UMVs as 'vessels' under the present definition in COLREGs Rule 3(a), they proposed that the US Coast Guard sponsor an amendment to the definition of a vessel 'Restricted in her Ability to Manoeuvre' (RAM) in Rule 3(g) to add 'a self-propelled vessel while unmanned and operating autonomously.'

As drafted, the NAVSAC proposal appears to implicitly assume that an unmanned and autonomously operated vehicle qualifies as a 'vessel' under Rule 3(a). It also necessarily concludes that, if unmanned and operating autonomously, such a vehicle is "a vessel which from the nature of her work is restricted in her ability to manoeuvre as required by these Rules and is therefore unable to keep out of the way of another vessel" (emphasis added). To use the pre-1972 COLREGs language, such UMVs would be 'privileged' over most manned vessels, at least in conditions where visibility is not restricted.

A second NAVSAC recommendation proposes to amend Rule 5 to exclude UMVs from the look-out requirement. Under the NAVSAC recommendation, Rule 5 would be amended by adding the qualifier 'manned' before 'vessel' as follows:

"Every manned vessel shall at all times maintain a proper look-out by sight and hearing as well as by all available means appropriate in the prevailing circumstances and conditions so as to make a full appraisal of the situation and of the risk of collision."

The amended NAVSAC rule would thus relieve UMVs from any look-out requirement, though not the related obligations under COLREGs Rule 7 (Risk of Collision), or the arguably broader obligations imposed by Rule 2 (Responsibility). Both of these NAVSAC recommendations are likely to prove controversial, as are some of the other recommendations (including an Automatic Identification System [AIS] carriage requirement for UUVs) not discussed here. For example, the fact that some 'stealth' UMVs are intentionally designed to avoid detection casts doubt on a regime that would require other vessels to keep out of their way. As of now, the US Coast Guard has not yet decided whether to adopt the NAVSAC recommendations or to carry the proposal to the International Maritime Organization (IMO), which has cognizance over the COLREGs.

4. THE MANNED-UNMANNED VEHICLE CONVERGENCE. As one considers the rapidly developing e-navigation concept (IMO, 2012) it seems likely that the distinction between manned and unmanned vehicles will blur in the coming years. Manned vessels are becoming increasingly automated, leading some to debate whether the most appropriate paradigm for the bridge watch officer of the future is an active and engaged 'navigating' watch officer, or a more passive 'monitoring' watch officer. As automation of navigation and collision avoidance functions increasingly takes the human watch officer out of the loop, the functional difference between an unmanned marine vehicle and a manned vessel with a monitoring watch officer begins to disappear.

Given present trends, one might soon encounter two watercraft of nearly identical design and equipped with identical sensors and navigation and collision avoidance 
equipment and programming (indeed, the same watercraft might operate alternately in manned and unmanned modes). Both could be engaged in the same 'work' and both might be equally 'manoeuvrable.' The only difference would be that one still carries a person who monitors a craft that is fully autonomous while the other is completely unmanned.

In both cases, control, including navigation and collision avoidance decisions and execution, would be carried out by the installed equipment and their programmed algorithms. Under those circumstances, should the COLREGs distinguish between the two vessels on the basis that one is manned and one is not-relieving one of the look-out obligation and according it RAM status? Or should both vehicles fall within the same classification, because both operate autonomously on the navigable waters? If the latter, what should that classification be? Should they be treated like vessels engaged in dredging or servicing aids to navigation or, perhaps, the less favoured category of seaplanes?

5. CONCLUSIONS. These questions could lead some to wonder whether it might be time to ask whether any analysis regarding application of the COLREGs to UMVs should also consider the ramifications for manned, but increasingly automated vessels. As we commemorate the $40^{\text {th }}$ anniversary of the 1972 COLREGs, perhaps it is time to assess whether navigation and collision avoidance technology, vessel manning and automation trends and the role of shore-side vessel traffic information and control systems have evolved to the point where the collision regulations should be comprehensively re-examined, to ensure that any changes to the rules will be robust across all reasonably foreseeable future applications.

\section{REFERENCES}

COLREGs (1972). International Regulations for Preventing Collisions at Sea 1972, with amendments adopted from December 2009. IMO Publications, London.

IMO [International Maritime Organization] (2012). E-navigation. (http://www.imo.org/ourwork/safety/ navigation/pages/enavigation.aspx).

NAVSAC (2011). NAVSAC Resolution 11-02. US Navigation Safety Advisory Council.

USV (2007). The US Navy Unmanned Surface Vehicle (USV) Master Plan, 23 July 2007. (http://www.navy. mil/navydata/technology/usvmppr.pdf).

UUV (2004). The US Navy Unmanned Undersea Vehicle (UUV) Master Plan, 9 November 2004. (http://www.navy.mil/navydata/technology/uuvmp.pdf). 